University of Nebraska - Lincoln

DigitalCommons@University of Nebraska - Lincoln

Food and Drug Administration Papers

U.S. Department of Health and Human Services

2019

\title{
Associations of risk factors of e-cigarette and cigarette use and susceptibility to use among baseline PATH study youth participants (2013-2014)
}

\author{
Michael D. Sawdey \\ Food and Drug Administration, Silver Spring, Michael.Sawdey@fda.hhs.gov \\ Hannah R. Day \\ Food and Drug Administration, Silver Spring \\ Blair Coleman \\ Food and Drug Administration, Silver Spring \\ Lisa D. Gardner \\ Food and Drug Administration, Silver Spring \\ Sarah E. Johnson

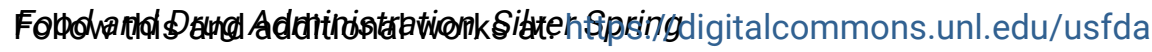 \\ Part of the Dietetics and Clinical Nutrition Commons, Health and Medical Administration Commons,

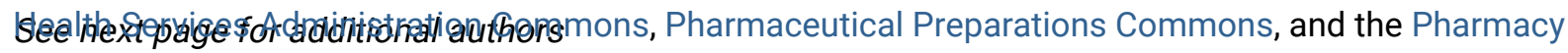 \\ Administration, Policy and Regulation Commons
}

Sawdey, Michael D.; Day, Hannah R.; Coleman, Blair; Gardner, Lisa D.; Johnson, Sarah E.; Limpert, Jean; Hammad, Hoda T.; Goniewicz, Macieji L.; Abrams, David B.; Stanton, Cassandra A.; Pearson, Jennifer L.; Kaufman, Annette R.; Kimmel, Heather L.; Delnevo, Cristine D.; Compton, Wilson M.; Bansal-Travers, Maansi; Niaura, Raymond S.; Hyland, Andrew; and Ambrose, Bridget K., "Associations of risk factors of ecigarette and cigarette use and susceptibility to use among baseline PATH study youth participants (2013-2014)" (2019). Food and Drug Administration Papers. 55.

https://digitalcommons.unl.edu/usfda/55

This Article is brought to you for free and open access by the U.S. Department of Health and Human Services at DigitalCommons@University of Nebraska - Lincoln. It has been accepted for inclusion in Food and Drug Administration Papers by an authorized administrator of DigitalCommons@University of Nebraska - Lincoln. 
Authors

Michael D. Sawdey, Hannah R. Day, Blair Coleman, Lisa D. Gardner, Sarah E. Johnson, Jean Limpert, Hoda T. Hammad, Macieji L. Goniewicz, David B. Abrams, Cassandra A. Stanton, Jennifer L. Pearson, Annette R. Kaufman, Heather L. Kimmel, Cristine D. Delnevo, Wilson M. Compton, Maansi Bansal-Travers, Raymond S. Niaura, Andrew Hyland, and Bridget K. Ambrose 


\title{
Associations of risk factors of e-cigarette and cigarette use and susceptibility to use among baseline PATH study youth participants (2013-2014)
}

\author{
Michael D. Sawdey, ${ }^{\mathrm{a}, *}$, Hannah R. Day ${ }^{\mathrm{a}}$, Blair Coleman ${ }^{\mathrm{a}}$, Lisa D. Gardner ${ }^{\mathrm{a}}$, Sarah E. Johnson ${ }^{\mathrm{a}}$, \\ Jean Limpert ${ }^{\mathrm{a}}$, Hoda T. Hammad ${ }^{\mathrm{a}}$, Maciej L. Goniewicz ${ }^{\mathrm{b}}$, David B. Abrams ${ }^{\mathrm{c}}$, \\ Cassandra A. Stanton ${ }^{\text {d,e }}$, Jennifer L. Pearson ${ }^{f}$, Annette R. Kaufman ${ }^{g}$, Heather L. Kimmel ${ }^{\text {h }}$, \\ Cristine D. Delnevo ${ }^{\mathrm{i}}$, Wilson M. Compton ${ }^{\mathrm{h}}$, Maansi Bansal-Travers ${ }^{\mathrm{b}}$, Raymond S. Niaura ${ }^{\mathrm{c}}$, \\ Andrew Hyland ${ }^{\mathrm{b}}$, Bridget K. Ambrose ${ }^{\mathrm{a}}$ \\ ${ }^{a}$ Office of Science, Center for Tobacco Products, Food and Drug Administration, Silver Spring, MD, USA \\ ${ }^{\mathrm{b}}$ Department of Health Behavior, Division of Cancer Prevention \& Population Sciences, Roswell Park Cancer Institute, Buffalo, NY, USA \\ ${ }^{\mathrm{c}}$ Department of Social and Behavioral Sciences, NYU College of Global Public Health, New York University, New York, NY, USA \\ ${ }^{\mathrm{d}}$ Westat, Rockville, MD, USA \\ ${ }^{\mathrm{e}}$ Department of Oncology, Lombardi Comprehensive Cancer Center, Georgetown University Medical Center, Washington, DC, USA \\ ${ }^{\mathrm{f}}$ Division of Social and Behavioral Sciences/Health Administration and Policy, University of Nevada, Reno, Reno, NV, USA \\ ${ }^{g}$ Tobacco Control Research Branch, Behavioral Research Program, Division of Cancer Control and Population Sciences, National Cancer Institute, National Institutes of \\ Health, Rockville, MD, USA \\ ${ }^{\mathrm{h}}$ National Institute on Drug Abuse, National Institutes of Health, U.S. Department of Health and Human Services, Bethesda, MD, USA \\ ${ }^{i}$ Department of Health Education and Behavioral Science, Center for Tobacco Studies, Rutgers School of Public Health, Piscataway, NJ, USA
}

\section{H I G H L I G H T S}

- Dual users had higher odds of reporting traditional risk factors for smoking, followed by single product users.

- Youth susceptible to both products had stronger associations with risk factors than those susceptible to one product.

- Between Wave 1 and 2, compared to continued non-users, a significantly higher proportion of new users reported being older, ever using marijuana and alcohol, having more internalizing, externalizing, and sensation seeking behaviors, having lower grades, and having someone in the household who uses tobacco.

\section{A R T I C L E I N F O}

\section{Keywords:}

E-cigarettes

Cigarettes

Risk factors of tobacco use

Susceptibility

\begin{abstract}
A B S T R A C T
Introduction: Improved understanding of the distribution of traditional risk factors of cigarette smoking among youth who have ever used or are susceptible to e-cigarettes and cigarettes will inform future longitudinal studies examining transitions in use.

Methods: Multiple logistic regression analysis was conducted using data from youth (ages 12-17 years) who had ever heard of e-cigarettes at baseline of the PATH Study $(n=12,460)$ to compare the distribution of risk factors for cigarette smoking among seven mutually exclusive groups based on ever cigarette/e-cigarette use and susceptibility status.

Results: Compared to committed never users, youth susceptible to e-cigarettes, cigarettes, or both had increasing odds of risk factors for cigarette smoking, with those susceptible to both products at highest risk, followed by cigarettes and e-cigarettes. Compared to e-cigarette only users, dual users had higher odds of nearly all risk factors (aOR range $=1.6-6.8$ ) and cigarette only smokers had higher odds of other (non-e-cigarette) tobacco use (aOR range $=1.5-2.3$ ), marijuana use $(\mathrm{aOR}=1.9,95 \% \mathrm{CI}=1.4-2.5)$, a high GAIN substance use score $(\mathrm{aOR}=1.9,95 \% \mathrm{CI}=1.1-3.4)$, low academic achievement (aOR range $=1.6-3.4)$, and exposure to smoking (aOR range $=1.8-2.1$ ). No differences were observed for externalizing factors (depression, anxiety, etc.), sensation seeking, or household use of non-cigarette tobacco.

Conclusions: Among ever cigarette and e-cigarette users, dual users had higher odds of reporting traditional risk
\end{abstract}

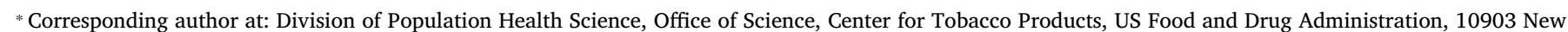
Hampshire Avenue, Silver Spring, MD 20903-1058, USA.

E-mail address: Michael.Sawdey@fda.hhs.gov (M.D. Sawdey). 
factors for smoking, followed by single product cigarette smokers and e-cigarette users. Understanding how ecigarette and cigarette users differ may inform youth tobacco use prevention efforts and advise future studies assessing probability of progression of cigarette and e-cigarette use.

\section{Background}

In the United States (U.S.), the prevalence of e-cigarette use among youth dramatically increased from 2011 to 2016, with e-cigarettes becoming the most commonly used tobacco product.(Jamal, Gentzke, Hu, et al., 2017; Miech, Johnston, O'Malley, Bachman, \& Schulenberg, 2016) Concurrently, youth cigarette smoking declined to historic lows. (Jamal et al., 2017; Miech et al., 2016) The trends of increased e-cigarette use and declining smoking could indicate that youth at risk for tobacco use are replacing cigarettes with e-cigarettes;(Kozlowski \& Warner, 2017) however, it is also possible that youth who otherwise might have never smoked conventional cigarettes are trying e-cigarettes.(Barrington-Trimis, Berhane, Unger, et al., 2015; Soneji, Barrington-Trimis, Wills, et al., 2017; Soneji, Sung, Primack, Pierce, \& Sargent, 2018; Wills et al., 2017) The 2018 National Academies of Science, Engineering and Medicine Report summarized three hypotheses explaining the relationship between youth e-cigarette use and cigarette smoking:(National Academies of Sciences, Engineering, and Medicine, 2018) 1) the diversion hypothesis suggests that high-risk youth with a proclivity for risk-taking behavior who might otherwise smoke cigarettes now use e-cigarettes instead; 2) the common liability hypothesis suggests that positive associations between e-cigarette use and cigarette smoking are due to shared risk factors; and 3) the catalyst hypothesis suggests that low-risk youth, who would otherwise not be susceptible to cigarette smoking, are drawn to e-cigarette use, which in turn increases proclivity for cigarette smoking. As a foundational first step in testing these hypotheses, a comprehensive baseline assessment of how traditional risk factors for cigarette smoking apply to youth who have ever used, or are susceptible to e-cigarette use, provides evidence of the feasibility of these theories. For instance, similar baseline risk profiles between e-cigarette and cigarette users could support the notion of shared vulnerability driving product use.

PATH data (Waves 1 and 2) has demonstrated that susceptibility to e-cigarettes and cigarettes predicts use one year later,(Pierce, Sargent, White, et al., 2017) however, information on the role individual risk factors play in the pathway between susceptibility and use is limited. Analyses of baseline PATH data suggests that minority youth have greater susceptibility to e-cigarettes and that most youth ever users of ecigarettes are susceptible to cigarettes.(Hampson, Andrews, Severson, \& Barckley, 2015) A study of youth susceptible to e-cigarettes suggested that psychological problems, rebelliousness, other substance use, and household exposure to smoking are determinants of e-cigarette use susceptibility.(Kwon, Seo, Lin, \& Chen, 2018) Additionally, studies have documented similarities and differences in risk factors associated with e-cigarette and cigarette use.(Barrington-Trimis et al., 2015; Wills, Knight, Williams, Pagano, \& Sargent, 2015) E-cigarette use and cigarette smoking may be associated with similar psychosocial factors such as: use among friends, use among people at home, friends' attitudes, sensation seeking, substance use, and internalizing/externalizing behaviors;(Barrington-Trimis et al., 2015; Wills et al., 2015) however, both e-cigarette and cigarette single product users may have fewer risk factors compared to those who report using both products (i.e., dual users).(Barrington-Trimis et al., 2015; Leventhal, Strong, Sussman, et al., 2016; Wills et al., 2015) For example, a study of 9th and 10th graders in Hawaii found e-cigarette only users were distinct from nonusers, but similar to cigarette only smokers, although e-cigarette users consistently had lower risk status compared to dual users.(Wills et al., 2015; Wills et al., 2017)

Using baseline youth data from the Population Assessment of Tobacco and Health (PATH) Study, this study provides a detailed description of the distribution of traditional risk factors for cigarette smoking, comparing seven mutually exclusive groups based on cigarette smoking, e-cigarette use, and susceptibility status. This manuscript differs from previous work examining susceptibility and risk factors of smoking by presenting a wider range of factors specific to cigarette smokers alongside e-cigarette users, and explores how risk factors differ between susceptibility and ever use groups. By providing a comprehensive characterization of traditional risk factors for smoking among youth who at baseline exhibited susceptibility or ever use of cigarettes, e-cigarettes or both, this analysis provides a descriptive foundation from which future PATH use trajectory analyses can build from (whether assessing risk for progression among ever users or initiation among susceptibles). Lastly, to further describe youth e-cigarette users, we assessed lifetime history of use, frequency of e-cigarette use, and reasons for use among youth past 30-day e-cigarette users at study baseline.

\section{Methods}

The study population for this analysis includes 12,460 youth (ages 12-17 years) who reported having ever heard of e-cigarettes out of a total of 13,651 PATH Study Wave 1 (September 2013-December 2014) youth participants ( $\mathrm{N}=11,978$ for Wave 1 to Wave 2 analysis). In the survey instrument, youth who had not heard of e-cigarettes were skipped out of questions pertaining to ever use and susceptibility, so they could not be classified for this analysis. Detailed sampling and study methodology have been published elsewhere.(Hyland, Ambrose, Conway, et al., 2017; U.S. Department of Health and Human Services et al., 2017) The PATH Study is a nationally representative householdbased longitudinal study sponsored by the National Institute of Health's National Institute of Drug Abuse and the Food and Drug Administration's Center for Tobacco Products and implemented by Westat. The PATH Study utilizes Audio-Computer Assisted Self-Interviews (ACASI) available in English and Spanish to collect information on tobacco use patterns and associated behaviors on youth and parent use of tobacco products, and provides images, text descriptors, and brand examples to aid in product recognition. The weighted response rate for the household screener was $54 \%$, and among households completing the screener, the youth weighted response rate in Wave 1 was $78.4 \%$. Weighting procedures further adjust for nonresponse. Parents/guardians provided consent and youth assented to study participation. Westat's Institutional Review Board approved the study design and protocol and the Office of Management and Budget approved the data collection.

\subsection{Measures}

\subsubsection{E-cigarette susceptibility and use}

Youth respondents who had heard of e-cigarettes were asked if they had ever used e-cigarettes, even one or two times. Susceptibility to future use was assessed among never users who reported having heard of the product using a three-item enhanced susceptibility scale:(Pierce et al., 2017; Pierce, Choi, Gilpin, Farkas, \& Merritt, 1996) "Have you ever been curious about using e-cigarettes?" (response options: very curious; somewhat curious; a little curious; not at all curious); "Do you think you will try an e-cigarette soon?" and "If one of your best friends were to offer you an e-cigarette, would you use it?" (response options for both: definitely yes; probably yes; probably not; definitely not). Responses signifying the strongest rejection (not at all curious/definitely not) on all three measures were considered committed never users; 
respondents with a combination of missing information and responses other than the strongest rejection of the three susceptibility responses were classified as susceptible. Respondents with a combination of the strongest rejection plus missing information were classified as missing.

\subsubsection{Cigarette smoking susceptibility and use}

All respondents were asked whether they had ever smoked a cigarette, even one or two times. Susceptibility to future cigarette smoking was assessed among never smokers utilizing three items. Two of the items were identical to those asked for e-cigarettes: "Have you ever been curious about using cigarettes?" and "If one of your best friends were to offer you a cigarette, would you use it?"(Pierce et al., 2017) The third question for cigarettes was: "Do you think you will smoke a cigarette in the next year? (response options: definitely yes; probably yes; probably not; definitely not).(Pierce et al., 2017) Responses signifying other than the strongest rejection (not at all curious/definitely not) on all three measures were considered susceptible to future cigarette smoking; missing responses were handled similarly to e-cigarette susceptibility.

\subsubsection{Definitions of e-cigarette and cigarette susceptibility and ever use}

Based on the criteria above, respondents were classified into one of seven mutually exclusive groups: 1 ) not susceptible to and have never tried e-cigarettes or cigarettes (committed never users), 2) never users susceptible to e-cigarettes, but not cigarettes (susceptible to e-cigarettes only), 3) never users susceptible to cigarettes, but not e-cigarettes (susceptible to cigarettes only), 4) never users susceptible to both e-cigarettes and cigarettes (susceptible to e-cigarettes and cigarettes), 5) ever e-cigarette users who have never tried cigarettes (e-cigarette only users), 6) ever cigarette smokers who have never tried e-cigarettes (cigarette only users), and 7) dual e-cigarette and cigarette ever users/smokers (dual users). Other tobacco use was not taken into consideration in creating these groups.

\subsubsection{Past 30-day e-cigarette and cigarette use}

To further characterize e-cigarette use among youth at baseline, patterns of e-cigarette use among those who had ever heard of e-cigarettes and reported use in the past 30-days were explored. Detailed patterns of current e-cigarette use including duration of use, frequency of use, and use of flavors were compared among: (1) current e-cigarette only users; (2) current e-cigarette and ever cigarette users (who may also have used other products); (3) and current e-cigarette users and ever users of at least one other non-cigarette tobacco product (including: traditional cigars, cigarillos, filtered cigars, snus pouches, smokeless, hookah, pipe, dissolvables, bidis, or kreteks). Additionally, past 30-day e-cigarette users who reported having used a lifetime equivalent of at least one disposable e-cigarette or cartridge and had used an e-cigarette in the past 30 days were asked about their reasons for use, stratified by cigarette smoking status.

\subsubsection{Known risk factors for cigarette smoking}

Covariates for analysis were selected based on known risk factors for youth cigarette smoking.(National Academies of Sciences, Engineering, and Medicine, 2018; U.S. Department of Health and Human Services, 2016; Conway et al., 2018) Demographic variables included age, sex, and race/ethnicity. Missing data on demographics and education were imputed as described in the PATH Study Restricted Use Files User Guide. Household exposure to tobacco use was explored by assessing cigarette smoking and tobacco use among household members, as well as any exposure to others smoking within the past seven days. Ever use of marijuana and alcohol were assessed. Internalizing factors (depression, anxiety, distress, and trouble sleeping) and externalizing factors (having a hard time paying attention, having a hard time listening to directions, lying to get what you want, bullied or threatened others, started a physical fight, felt restless, and answered before the other person finished asking the question) were also assessed. Severity of substance abuse symptoms, internalizing, and externalizing disorders were assessed using subscales of the Global Appraisal of Individual Needs Short Screener (GAIN-SS) (Dennis et al., 2006). Problems experienced within the past year were tallied and dichotomized by severity, with four or more problems reported in the past year categorized as a high substance use, internalizing, and externalizing disorder score. Sensation-seeking was assessed via three modified items from the Brief Sensation Seeking Scale: 1) "I like to do frightening things", 2) "I like new and exciting experiences even if I have to break the rules", and 3) "I prefer friends who are exciting and unpredictable" (Hoyle et al., 2002). Response options ranged from strongly disagree (0) to strongly agree (4) and were summed to create an overall score (range: 0-12), which was dichotomized at the upper quartile for analysis (score $\geq 6$ indicated high sensation seeking). The Brief Sensation Seeking Scale was found to be internally consistent in the PATH Study (Cronbach's $\alpha=0.76$ ). Parent-reported past-year academic achievement was categorized into four grade levels: mostly A's or A's and B's; mostly B's or B's and C's; mostly C's or C's and D's; or lower.

\subsection{Statistical analysis}

Analyses were conducted using SAS 9.4, utilizing replicate weights and balanced repeated replication to account for the PATH Study's complex survey design. At baseline, descriptive statistics were used to explore the distribution of known risk factors by susceptibility and ever use of cigarettes and e-cigarettes. Multinomial logistic regression, adjusted for age, race/ethnicity, and sex, was used to evaluate associations between known risk factors for cigarette smoking and susceptibility to or ever use of e-cigarettes and cigarettes. In the first model, those susceptible to e-cigarettes only, cigarettes only, or both products were compared to committed never users. In the second model, committed never users, cigarette only smokers, and dual users were compared to e-cigarette only users. Characteristics and patterns of e-cigarette use in the past 30-days, in addition to reasons for use, were then examined by current tobacco use status. Lastly, we explored the distribution of known risk factors among youth who were never tobacco users at baseline (Wave 1) who either continued to be never users or became new users of e-cigarettes only, cigarettes only, or both products at follow-up (Wave 2). Rao-Scott chi-squares were used to test for significant differences where appropriate.

\section{Results}

Among all youth at PATH Study Wave 1, 91.4\% $(\mathrm{n}=12,460)$ had heard of e-cigarettes (all percentages are weighted; all n's are unweighted). Of these, $81.4 \%$ were non-users of e-cigarettes or cigarettes, with $46.0 \%$ committed never users $(\mathrm{n}=5701), 7.2 \%$ susceptible to ecigarettes $(n=894), 10.1 \%$ susceptible to cigarettes $(n=1263)$, and $18.1 \%$ susceptible to both e-cigarettes and cigarettes $(n=2276)$. Additionally, $18.5 \%$ of youth were ever users of either product, with $3.9 \%$ e-cigarette only users $(n=488), 6.9 \%$ cigarette only smokers $(n=875)$, and $7.7 \%$ dual users $(n=963)$. Detailed information on the distribution of demographic, behavioral, and psychosocial characteristics is presented in Supplemental Table 1.

\subsection{Risk factors and susceptibility to e-cigarettes, cigarettes, or both products}

Committed never users had the lowest percentage of youth reporting all risk factors (Supplemental Table 1). Compared to committed never users, those susceptible to e-cigarettes only, cigarettes only, or both products had significantly higher odds of each risk factor assessed after controlling for age, race/ethnicity, and sex (Table 1). In many instances, the magnitude of the observed associations was similar between those susceptible to e-cigarettes only and cigarettes only compared to committed never users, and larger for those susceptible to both 
Table 1

Multinomial logistic regression of demographic and psychosocial correlates related to tobacco use by susceptibility to cigarettes and e-cigarettes-PATH Study Wave 1 Data (2013-2014).

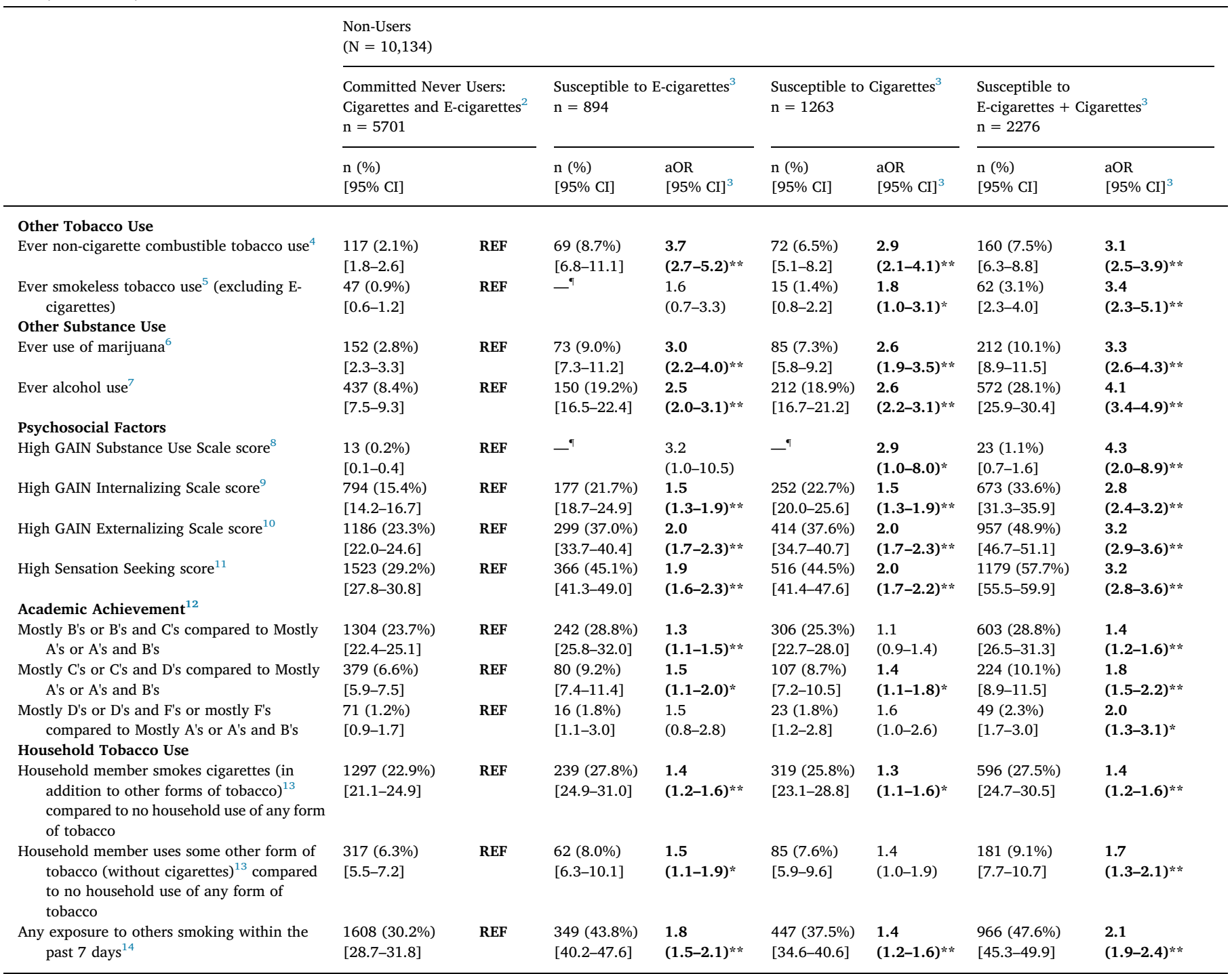

Estimates in bold are statistically significantly different, * indicates $\mathrm{p}<0.05$ and $* *$ indicates $\mathrm{p}<0.001$; ${ }^{\circ}$ Estimate not presented because relative standard error $\geq 30 \%$ or denominator $<50$.

${ }^{1}$ Covariates included in the multinomial logistic models include age, treated as a continuous variable; sex, treated dichotomously (male or female); race, categorized as white race alone, black race alone, Asian race alone, or other race, including multiracial; and Hispanic ethnicity, categorized as Hispanic or non-Hispanic.

${ }^{2}$ A total of 353 committed never users of cigarettes and e-cigarettes had missing covariates (i.e., age, sex, race, or ethnicity) and were dropped from the model.

${ }^{3}$ A total of 70 susceptible to e-cigarettes, 103 susceptible to cigarettes, and 205 susceptible to both cigarettes and e-cigarette users had missing covariates and were dropped from the model. Susceptibility to products other than e-cigarettes or cigarettes was not assessed.

${ }^{4}$ Youth who reported ever smoking a traditional cigar, cigarillo, or filtered cigar, even one or two times; ever smoking a pipe filled with tobacco, even one or two puffs; ever smoking tobacco in a hookah, even one or two puffs; or having tried a bidi or kretek, even one or two times were classified as ever non-cigarette combustible product users. A combination of missing data and "no's" to any of the products included in this variable were counted as missing (n $=10$ ).

5 Youth who reported ever having used snus pouches, loose snus, moist snuff, dip, spit or chewing tobacco, or dissolvable tobacco products (such as Ariva, Stonewall or Camel Orbs, Sticks or Strips), even one or two times were classified as ever smokeless tobacco product users. A combination of missing data and "no's" to any of the products included in this variable (i.e., YS1002_01, YS1002_02, YU1003, and YD1002) were counted as missing $(n=89)$.

${ }^{6}$ Youth were asked "Have you ever used marijuana, hash, THC, grass, pot or weed? (Yes/No)", unless they had previously reported having ever smoked part or all of a cigar, cigarillo, or filtered cigar with marijuana in it. Affirmative responses to either question classified as an ever marijuana user ( $\mathrm{n}=35 \mathrm{missing}$ ).

7 All youth were asked "Have you ever used alcohol at all, including sips of someone's drink or your own drink?" (Yes/No). Those that answered affirmatively were asked "About how old were you when you had your first alcoholic drink, other than small tastes or sips?" Those indicating that "I have never had an alcoholic drink other than small tastes or sips" were reclassified as never users for the purpose of this analysis. Those who did not know or refused to answer: 1 ) if they had ever used alcohol at all, or 2) the age when they first had an alcoholic drink were excluded from this variable ( $\mathrm{n}=49$ missing).

8 The GAIN-SS Substance Use subscale consists of seven items: (1) used alcohol or other drugs weekly or more often; (2) spent a lot of time getting alcohol or other drugs; (3) spent a lot of time using or recovering from alcohol or other drugs; (4) kept using alcohol or other drugs, even though it was causing social problems, leading to fights, or getting into trouble with other people; (5) use of alcohol or other drugs caused reduced involvement in activities at work, school, home, or social events; (6) withdrawal problems; and (7) use of alcohol or other drugs to stop being sick or avoid withdrawal problems. Youth were asked to report whether they had experienced each problem: within the past month; 2-12 months ago; over a year ago; never; or don't know/refused. Problems experienced within the past year were tallied and dichotomized by severity, with four or more problems reported in the past year categorized as a high score ( $\mathrm{n}=253 \mathrm{missing}$; includes those missing 
responses for any of the scale items).

9 The GAIN-SS Internalizing subscale consists of four items, asking about the last time you had significant problems with: (1) feeling very trapped, lonely, sad,

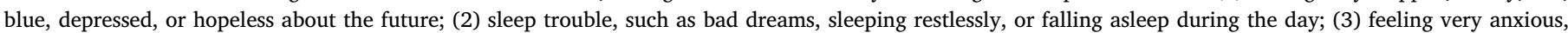

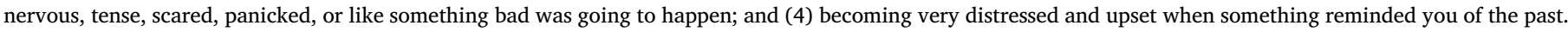

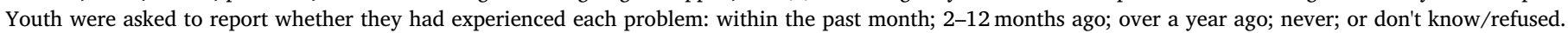

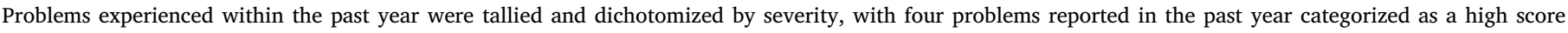
( $n=206$ missing; includes those missing responses for any of the scale items).

10 The GAIN-SS Externalizing subscale consists of seven items, asking about the last time you did the following two or more times: (1) had a hard time paying

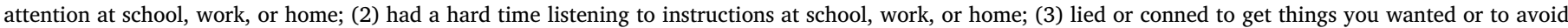

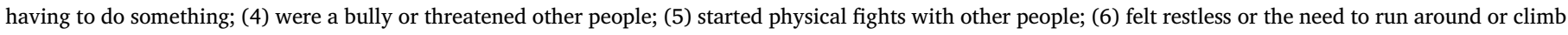

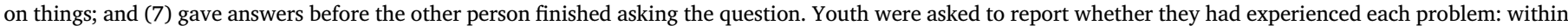

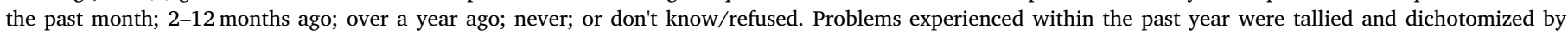

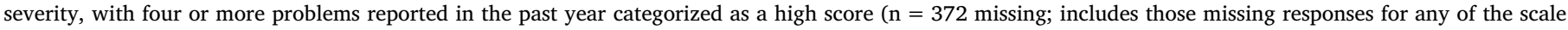
items).

11 Youth were asked to indicate whether they agreed or disagreed with the following three measures regarding sensation seeking: (1) I like to do frightening

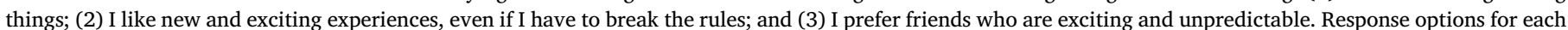

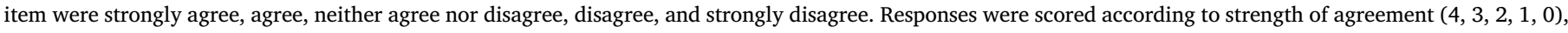

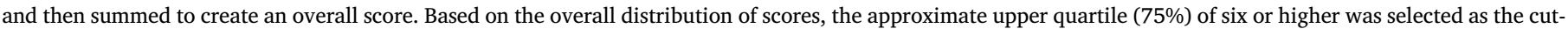

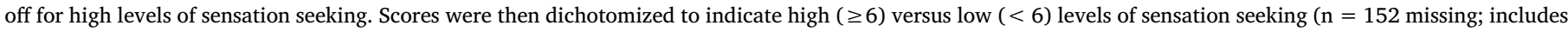
those missing responses for any of the scale items).

12 Academic achievement: $n=83$ missing (including $n=38$ where school was ungraded). This item was reported by parents in the parent interview.

13 All youth were asked "Does anyone who lives with you now do any of the following? Choose all that apply: 1) Smoke cigarettes; 2) Use smokeless tobacco, such

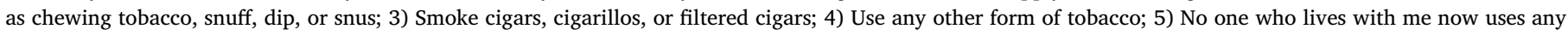

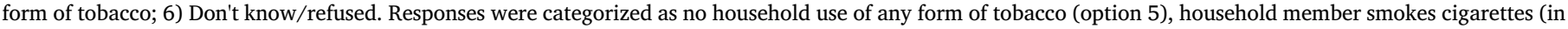

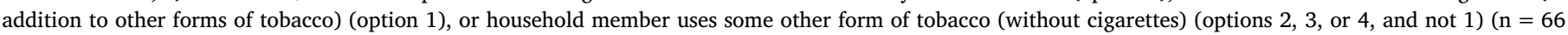
missing).

14 All youth were asked "During the past seven days, about how many hours were you around others who were smoking [whether or not you were smoking

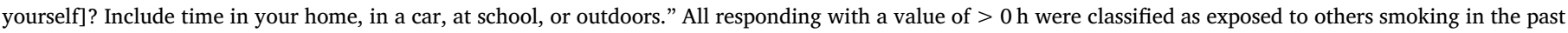
seven days $(\mathrm{n}=251$ missing).

products compared to those susceptible to one (Table 1). For example, compared to committed never users, those susceptible to either e-cigarettes or cigarettes had approximately two and a half times the odds of ever trying alcohol (aOR e-cigarettes $=2.5,95 \% \mathrm{CI}=2.0-3.1)(\mathrm{aOR}$ cigarettes $=2.6,95 \% \mathrm{CI}=2.2-3.1$ ), whereas those susceptible to both had approximately four times the odds of ever trying alcohol ( $\mathrm{aOR}=4.1,95 \% \mathrm{CI}=3.4-4.9)$ compared with committed never users.

\subsection{Risk factors and ever use of e-cigarettes, cigarettes, or both products}

Compared to e-cigarette only users, committed never users had lower odds of each risk factor after controlling for age, race/ethnicity, and sex (Table 2). Between the ever use groups, differences and similarities were observed and, for some factors, a risk gradient emerged. For example, compared to ever e-cigarette only users, ever cigarette only smokers had twice the odds of ever using marijuana (aOR $=1.9$, $95 \% \mathrm{CI}=1.4-2.5$ ); the association was even stronger for dual users $(\mathrm{aOR}=5.5,95 \% \mathrm{CI}=4.0-7.5)$. Similar results were seen for the GAIN Substance Use scale; compared to ever e-cigarette only users, ever cigarette only smokers ( $\mathrm{aOR}=1.9,95 \% \mathrm{CI}=1.1-3.4$ ) and dual users $(\mathrm{aOR}=5.7,95 \% \mathrm{CI}=3.5-9.3)$ had increased odds of having high scores.

Similarities were seen between ever e-cigarette only and cigarette only users on GAIN Internalizing scale scores and alcohol use, although dual users had increased odds of both risk factors, a finding that remained after controlling for age, race/ethnicity, and sex (Table 2). Specifically, for GAIN Internalizing, no difference was seen between ever cigarette only smokers and e-cigarette users, but dual users had slightly higher odds of high GAIN Internalizing scores (aOR $=1.6,95 \%$ $\mathrm{CI}=1.2-2.0$ ) than ever e-cigarette users. Similar results were seen between ever cigarette only smokers and e-cigarette users, but dual users had higher odds of alcohol use than ever e-cigarette only users $(\mathrm{aOR}=1.8,95 \% \mathrm{CI}=1.4-2.4)$. No differences were seen between ever e-cigarette only, cigarette only, and dual users for low academic achievement, high GAIN Externalizing scores, and high sensation seeking scores, which persisted after adjusting for age, race/ethnicity, and sex.

Lastly, we examined the distribution of risk factors among never tobacco users at Wave 1 who were new e-cigarette, cigarette, or dual users at Wave 2 (Supplemental Table 3). Among new users at Wave 2, the percent reporting each risk factor at Wave 1 were similar, as demonstrated by overlapping confidence intervals; however, there were significant differences in the proportion reporting each risk factor comparing continued never users and all new users. New users of either or both products were generally older, had ever used marijuana, had a high score for internalizing factors, externalizing factors, and sensation seeking, had lower academic achievement, were exposed to smoking or other tobacco use in the household, or had been exposed to smoking in the last 7 days. A higher proportion of Hispanic youth and youth reporting ever alcohol use were new cigarette smokers compared to ecigarette only users.

\subsection{Patterns of e-cigarette use in past 30 days and reasons for use by smoking status}

Table 3 presents information for past 30-day e-cigarette use overall and by other tobacco use status (past 30-day: e-cigarette only use, ecigarette and cigarette use [may have used other products], and e-cigarette and other [non-cigarette] tobacco product use). Among the $3.0 \%$ of past 30 -day youth e-cigarette users $(\mathrm{n}=398), 37.0 \%$ used ecigarettes only in the past 30 days, $45.1 \%$ used e-cigarettes and cigarettes, and $17.8 \%$ used e-cigarettes and at least one non-cigarette tobacco product. Frequency of past 30-day e-cigarette use was generally low, with $73.4 \%$ having used on five or fewer days. There were no differences in frequency of e-cigarette use by other tobacco use status. Among past 30-day e-cigarette and cigarette users, $40.8 \%$ smoked cigarettes $1-5$ days and $39.6 \%$ smoked 20 or more days in past month. Furthermore, about half (50.6\%) of past 30-day e-cigarette users (including users of additional products) started in the last year, but when stratified by other tobacco use status, $62.2 \%$ e-cigarette only users started in the last year compared to only $39.2 \%$ of dual e-cigarette and cigarette users. 
Table 2

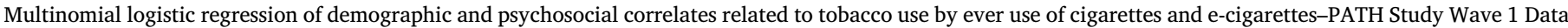
(2013-2014). ${ }^{1}$

\begin{tabular}{|c|c|c|c|c|c|c|c|c|}
\hline & \multirow{2}{*}{\multicolumn{2}{|c|}{$\begin{array}{l}\text { Committed Never Users: Cigarettes } \\
\text { and E-cigarettes }{ }^{2} \\
(\mathrm{n}=5701)\end{array}$}} & \multicolumn{6}{|c|}{$\begin{array}{l}\text { Ever Product Users } \\
(\mathrm{n}=2326)\end{array}$} \\
\hline & & & \multicolumn{2}{|c|}{$\begin{array}{l}\text { Ever E-cigarette Only } \\
\text { Users (no Cigarette } \\
\text { Smoking) } \\
(\mathrm{n}=488)\end{array}$} & \multicolumn{2}{|c|}{$\begin{array}{l}\text { Ever Cigarette Only Smokers (No } \\
\text { E-cigarette Use) } \\
(\mathrm{n}=875)\end{array}$} & \multicolumn{2}{|c|}{$\begin{array}{l}\text { Ever Dual E-cigarette and Cigarette } \\
\text { Users }{ }^{3} \\
(\mathrm{n}=963)\end{array}$} \\
\hline & $\begin{array}{l}\mathrm{n}(\%) \\
{[95 \% \mathrm{CI}]}\end{array}$ & $\begin{array}{l}\mathrm{aOR} \\
{[95 \% \mathrm{CI}]}\end{array}$ & $\begin{array}{l}\mathrm{n}(\%) \\
{[95 \% \mathrm{CI}]}\end{array}$ & & $\begin{array}{l}\mathrm{n}(\%) \\
[95 \% \mathrm{CI}])\end{array}$ & $\begin{array}{l}\mathrm{aOR} \\
{[95 \% \mathrm{CI}]}\end{array}$ & $\begin{array}{l}\text { n (\%) } \\
[95 \% \mathrm{CI}])\end{array}$ & $\begin{array}{l}\mathrm{aOR} \\
{[95 \% \mathrm{CI}]}\end{array}$ \\
\hline \multicolumn{9}{|l|}{ Other Tobacco Use } \\
\hline $\begin{array}{l}\text { Ever non-cigarette combustible } \\
\text { tobacco use }\end{array}$ & $\begin{array}{l}117(2.1 \%) \\
{[1.8-2.6]}\end{array}$ & $\begin{array}{l}0.06 \\
(0.05-0.08)^{* *}\end{array}$ & $\begin{array}{l}148(32.9 \%) \\
{[28.1-38.0]}\end{array}$ & REF & $\begin{array}{l}340(41.8 \%) \\
{[37.9-45.7]}\end{array}$ & $\begin{array}{l}1.5 \\
(1.1-2.0)^{*}\end{array}$ & $\begin{array}{l}670(72.6 \%) \\
{[69.4-75.6]}\end{array}$ & $\begin{array}{l}5.4 \\
(4.0-7.2)^{* *}\end{array}$ \\
\hline $\begin{array}{l}\text { Ever smokeless tobacco use }{ }^{5} \\
\text { (excluding E-cigarettes) }\end{array}$ & $\begin{array}{l}47(0.9 \%) \\
{[0.6-1.2]}\end{array}$ & $\begin{array}{l}0.10 \\
(0.06-0.15)^{* *}\end{array}$ & $\begin{array}{l}39(9.3 \%) \\
{[6.8-12.6]}\end{array}$ & REF & $\begin{array}{l}135(16.7 \%) \\
{[14.3-19.4]}\end{array}$ & $\begin{array}{l}2.3 \\
(1.5-3.3)^{* *}\end{array}$ & $\begin{array}{l}310(34.5 \%) \\
{[30.5-38.8]}\end{array}$ & $\begin{array}{l}4.9 \\
(3.2-7.5)^{* *}\end{array}$ \\
\hline \multicolumn{9}{|l|}{ Other Substance Use } \\
\hline Ever use of marijuana ${ }^{6}$ & $\begin{array}{l}152(2.8 \%) \\
{[2.3-3.3]}\end{array}$ & $\begin{array}{l}0.08 \\
(0.06-0.11)^{* *}\end{array}$ & $\begin{array}{l}142(32.0 \%) \\
{[27.9-36.5]}\end{array}$ & REF & $\begin{array}{l}394(47.6 \%) \\
{[43.3-52.0]}\end{array}$ & $\begin{array}{l}1.9 \\
(1.4-2.5)^{* *}\end{array}$ & $\begin{array}{l}656(71.4 \%) \\
{[67.9-74.7]}\end{array}$ & $\begin{array}{l}5.5 \\
(4.0-7.5)^{* *}\end{array}$ \\
\hline Ever alcohol use ${ }^{7}$ & $\begin{array}{l}437(8.4 \%) \\
{[7.5-9.3]}\end{array}$ & $\begin{array}{l}0.10 \\
(0.08-0.12) * *\end{array}$ & $\begin{array}{l}233(52.7 \%) \\
{[48.0-57.4]}\end{array}$ & REF & $\begin{array}{l}462(56.6 \%) \\
{[52.7-60.5]}\end{array}$ & $\begin{array}{l}1.0 \\
(0.8-1.4)\end{array}$ & $\begin{array}{l}643(71.3 \%) \\
{[68.2-74.3]}\end{array}$ & $\begin{array}{l}1.8 \\
(1.4-2.4)^{* *}\end{array}$ \\
\hline \multicolumn{9}{|l|}{ Psychosocial Factors } \\
\hline $\begin{array}{l}\text { High GAIN Substance Use Scale } \\
\text { score }^{8}\end{array}$ & $\begin{array}{l}13(0.2 \%) \\
{[0.1-0.4]}\end{array}$ & $\begin{array}{l}0.06 \\
(0.02-0.12)^{* *}\end{array}$ & $\begin{array}{l}20(4.1 \%) \\
{[2.6-6.4]}\end{array}$ & REF & $\begin{array}{l}59(7.8 \%) \\
{[5.9-10.1]}\end{array}$ & $\begin{array}{l}1.9 \\
(1.1-3.4)^{*}\end{array}$ & $\begin{array}{l}168(18.9 \%) \\
{[16.1-22.0]}\end{array}$ & $\begin{array}{l}5.7 \\
(3.5-9.3)^{* *}\end{array}$ \\
\hline High GAIN Internalizing Scale score ${ }^{9}$ & $\begin{array}{l}794(15.4 \%) \\
{[14.2-16.7]}\end{array}$ & $\begin{array}{l}0.39 \\
(0.31-0.49) * *\end{array}$ & $\begin{array}{l}141(30.9 \%) \\
{[26.8-35.3]}\end{array}$ & REF & $\begin{array}{l}315(39.0 \%) \\
{[35.2-43.0]}\end{array}$ & $\begin{array}{l}1.3 \\
(1.0-1.7)\end{array}$ & $\begin{array}{l}375(41.6 \%) \\
{[38.2-45.0]}\end{array}$ & $\begin{array}{l}1.6 \\
(1.2-2.0)^{* *}\end{array}$ \\
\hline $\begin{array}{l}\text { High GAIN Externalizing Scale } \\
\text { score }^{10}\end{array}$ & $\begin{array}{l}1186(23.3 \%) \\
{[22.0-24.6]}\end{array}$ & $\begin{array}{l}0.32 \\
(0.26-0.40)^{* *}\end{array}$ & $\begin{array}{l}212(47.7 \%) \\
{[42.6-52.8}\end{array}$ & REF & $\begin{array}{l}373(47.0 \%) \\
{[43.6-50.5]}\end{array}$ & $\begin{array}{l}1.0 \\
(0.8-1.2)\end{array}$ & $\begin{array}{l}457(51.7 \%) \\
{[48.4-55.0]}\end{array}$ & $\begin{array}{l}1.2 \\
(1.0-1.6)\end{array}$ \\
\hline High Sensation Seeking score ${ }^{11}$ & $\begin{array}{l}1523(29.2 \%) \\
{[27.8-30.8]}\end{array}$ & $\begin{array}{l}0.24 \\
(0.19-0.30)^{* *}\end{array}$ & $\begin{array}{l}296(66.0 \%) \\
{[60.9-70.6]}\end{array}$ & REF & $\begin{array}{l}484(60.1 \%) \\
{[55.9-64.2]}\end{array}$ & $\begin{array}{l}0.8 \\
(0.6-1.0)\end{array}$ & $\begin{array}{l}637(70.8 \%) \\
{[67.7-73.6]}\end{array}$ & $\begin{array}{l}1.2 \\
(0.9-1.5)\end{array}$ \\
\hline \multicolumn{9}{|l|}{ Academic Achievement ${ }^{12}$} \\
\hline $\begin{array}{l}\text { Mostly B's or B's and C's compared to } \\
\text { Mostly A's or A's and B's }\end{array}$ & $\begin{array}{l}1304(23.7 \%) \\
{[22.4-25.1]}\end{array}$ & $\begin{array}{l}0.6 \\
(0.5-0.8)^{* *}\end{array}$ & $\begin{array}{l}153(31.9 \%) \\
{[27.6-36.6]}\end{array}$ & REF & $\begin{array}{l}280(35.6 \%) \\
{[32.2-39.2]}\end{array}$ & $\begin{array}{l}1.6 \\
(1.2-2.1)^{*}\end{array}$ & $\begin{array}{l}326(36.8 \%) \\
{[33.5-40.4]}\end{array}$ & $\begin{array}{l}2.1 \\
(1.5-2.8)^{* *}\end{array}$ \\
\hline $\begin{array}{l}\text { Mostly C's or C's and D's compared to } \\
\text { Mostly A's or A's and B's }\end{array}$ & $\begin{array}{l}379(6.6 \%) \\
{[5.9-7.5]}\end{array}$ & $\begin{array}{l}0.5 \\
(0.3-0.7)^{* *}\end{array}$ & $\begin{array}{l}55(11.8 \%) \\
{[9.1-15.1]}\end{array}$ & REF & $\begin{array}{l}145(17.9 \%) \\
{[15.4-20.7]}\end{array}$ & $\begin{array}{l}2.4 \\
(1.6-3.5)^{* *}\end{array}$ & $\begin{array}{l}191(20.9 \%) \\
{[17.7-24.4]}\end{array}$ & $\begin{array}{l}3.4 \\
(2.2-5.1)^{* *}\end{array}$ \\
\hline $\begin{array}{l}\text { Mostly D's or D's and F's or mostly F's } \\
\text { compared to Mostly A's or A's and } \\
\text { B's }\end{array}$ & $\begin{array}{l}71(1.2 \%) \\
{[0.9-1.7]}\end{array}$ & $\begin{array}{l}0.5 \\
(0.2-1.0)^{*}\end{array}$ & $-\%$ & REF & $\begin{array}{l}44(4.9 \%) \\
{[3.6-6.6]}\end{array}$ & $\begin{array}{l}3.4 \\
{[1.5-7.5]}\end{array}$ & $\begin{array}{l}76(8.2 \%) \\
{[6.6-10.1]}\end{array}$ & 6.8 \\
\hline \multicolumn{9}{|l|}{ Household Tobacco Use } \\
\hline $\begin{array}{l}\text { Household member smokes cigarettes } \\
\text { (in addition to other forms of } \\
\text { tobacco) })^{13} \text { compared to no } \\
\text { household use of any form of } \\
\text { tobacco }\end{array}$ & $\begin{array}{l}1297(22.9 \%) \\
{[21,1-24.9]}\end{array}$ & $\begin{array}{l}0.5 \\
(0.4-0.7)^{* *}\end{array}$ & $\begin{array}{l}154(31.3 \%) \\
{[26.5-36.4]}\end{array}$ & REF & $\begin{array}{l}412(48.9 \%) \\
{[44.6-53.1]}\end{array}$ & $\begin{array}{l}2.1 \\
(1.7-2.8)^{* *}\end{array}$ & $\begin{array}{l}508(53.8 \%) \\
{[49.8-57.8]}\end{array}$ & $\begin{array}{l}2.8 \\
(2.0-3.8)^{* *}\end{array}$ \\
\hline $\begin{array}{l}\text { Household member uses some other } \\
\text { form of tobacco (without } \\
\text { cigarettes) }{ }^{13} \text { compared to no } \\
\text { household use of any form of } \\
\text { tobacco }\end{array}$ & $\begin{array}{l}317(6.3 \%) \\
{[5.5-7.2]}\end{array}$ & $\begin{array}{l}0.4 \\
(0.3-0.5)^{* *}\end{array}$ & $\begin{array}{l}54(12.8 \%) \\
{[9.6-16.8]}\end{array}$ & REF & $\begin{array}{l}82(10.4 \%) \\
{[8.5-12.6]}\end{array}$ & $\begin{array}{l}1.1 \\
(0.7-1.6)\end{array}$ & $\begin{array}{l}75(8.4 \%) \\
{[6.8-10.4]}\end{array}$ & $\begin{array}{l}0.9 \\
(0.6-1.4)\end{array}$ \\
\hline $\begin{array}{l}\text { Any exposure to others smoking } \\
\text { within the past } 7 \text { days }^{14}\end{array}$ & $\begin{array}{l}1608(30.2 \%) \\
{[28.7-31.8]}\end{array}$ & $\begin{array}{l}0.4 \\
(0.3-0.4)^{* *}\end{array}$ & $\begin{array}{l}253(54.3 \%) \\
{[49.7-58.9]}\end{array}$ & REF & $\begin{array}{l}551(68.1 \%) \\
{[64.8-71.3]}\end{array}$ & $\begin{array}{l}1.8 \\
(1.4-2.2) * *\end{array}$ & $\begin{array}{l}739(82.8 \%) \\
{[79.9-85.4]}\end{array}$ & $\begin{array}{l}4.2 \\
(3.2-5.4) * *\end{array}$ \\
\hline
\end{tabular}

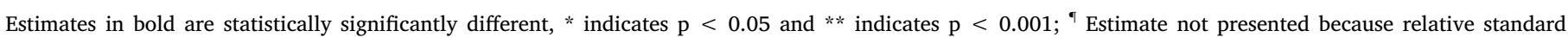
error $\geq 30 \%$ or denominator $<50$.

1 Covariates included in the multinomial logistic models include age, treated as a continuous variable; sex, treated dichotomously (male or female); race, cate-

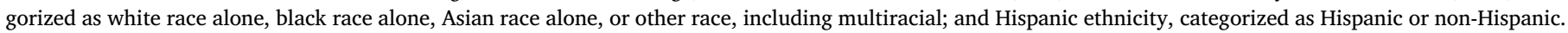

2 A total of 353 committed never users of cigarettes and e-cigarettes had missing covariates (i.e., age, sex, race, or ethnicity) and were dropped from the model.

3 A total of 33 ever e-cigarette, no cigarette users, 50 ever cigarette, no e-cigarette users, and 45 ever cigarette and e-cigarette users had missing covariates and were dropped from the model. Use of other tobacco products was not assessed in these groups.

4 Youth who reported ever smoking a traditional cigar, cigarillo, or filtered cigar, even one or two times; ever smoking a pipe filled with tobacco, even one or two

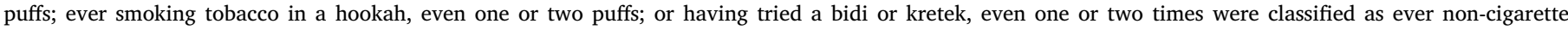
combustible product users. A combination of missing data and "no's" to any of the products included in this variable were counted as missing ( $\mathrm{n}=10$ ).

5 Youth who reported ever having used snus pouches, loose snus, moist snuff, dip, spit or chewing tobacco, or dissolvable tobacco products (such as Ariva,

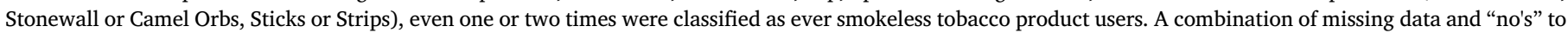
any of the products included in this variable (i.e., YS1002_01, YS1002_02, YU1003, and YD1002) were counted as missing ( $\mathrm{n}=89$ ).

6 Youth were asked "Have you ever used marijuana, hash, THC, grass, pot or weed? (Yes/No)", unless they had previously reported having ever smoked part or all of a cigar, cigarillo, or filtered cigar with marijuana in it. Affirmative responses to either question classified as an ever marijuana user ( $\mathrm{n}=35$ missing).

7 All youth were asked "Have you ever used alcohol at all, including sips of someone's drink or your own drink?" (Yes/No). Those that answered affirmatively were

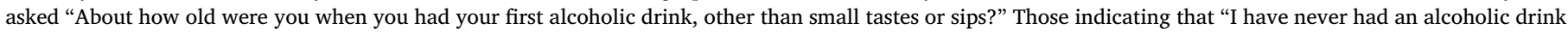

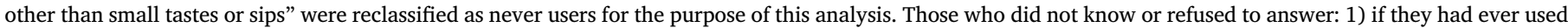
alcohol at all, or 2) the age when they first had an alcoholic drink were excluded from this variable ( $\mathrm{n}=49 \mathrm{missing}$ ).

8 The GAIN-SS Substance Use subscale consists of seven items: (1) used alcohol or other drugs weekly or more often; (2) spent a lot of time getting alcohol or other

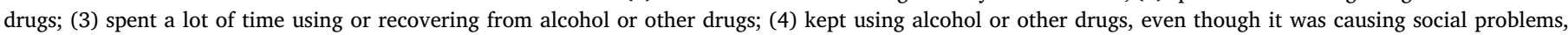

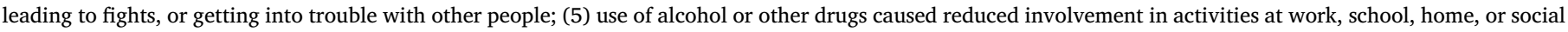




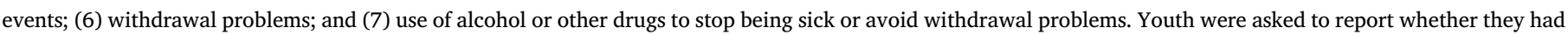

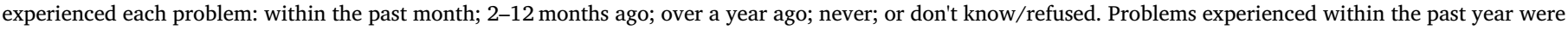

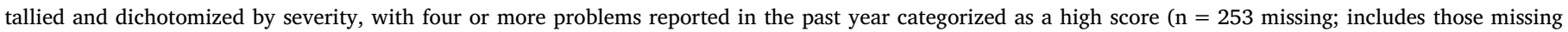
responses for any of the scale items).

9 The GAIN-SS Internalizing subscale consists of four items, asking about the last time you had significant problems with: (1) feeling very trapped, lonely, sad,

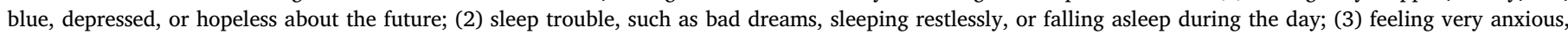

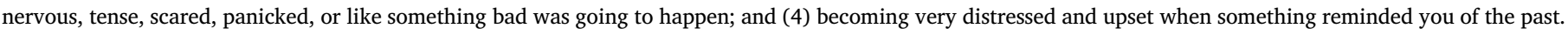

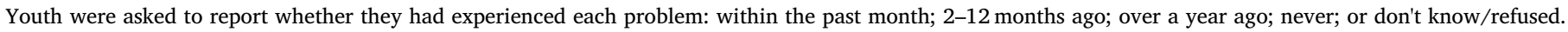

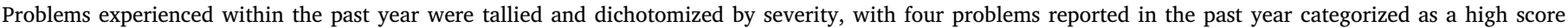
( $n=206$ missing; includes those missing responses for any of the scale items).

10 The GAIN-SS Externalizing subscale consists of seven items, asking about the last time you did the following two or more times: (1) had a hard time paying

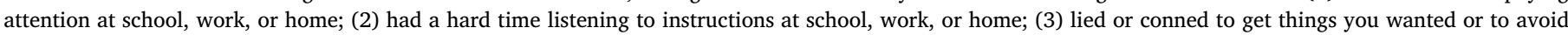

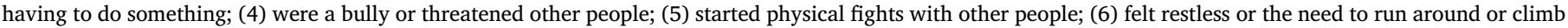

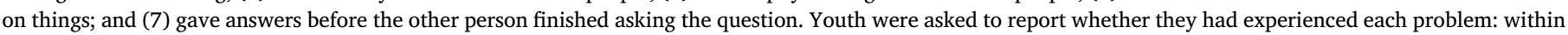

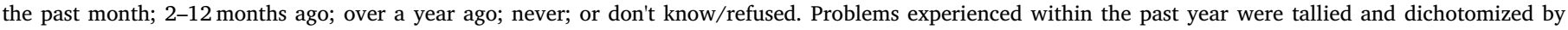

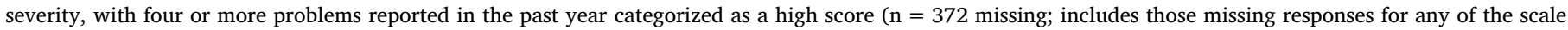
items).

11 Youth were asked to indicate whether they agreed or disagreed with the following three measures regarding sensation seeking: (1) I like to do frightening

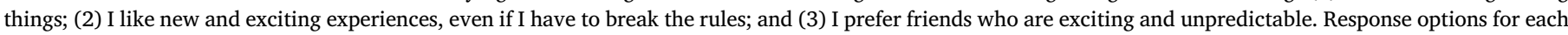

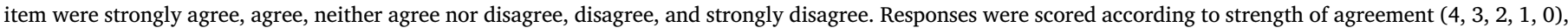

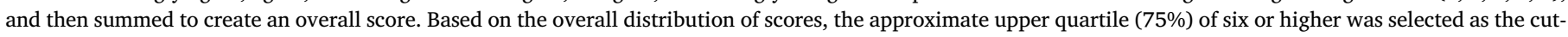

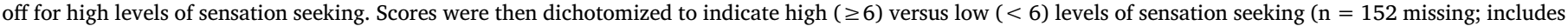
those missing responses for any of the scale items).

12 Academic achievement: $n=83$ missing (including $n=38$ where school was ungraded). This item was reported by parents in the parent interview.

13 All youth were asked "Does anyone who lives with you now do any of the following? Choose all that apply: 1) Smoke cigarettes; 2) Use smokeless tobacco, such

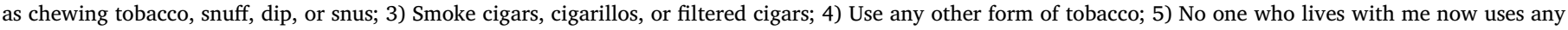

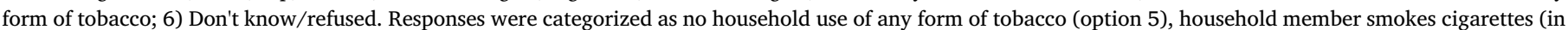

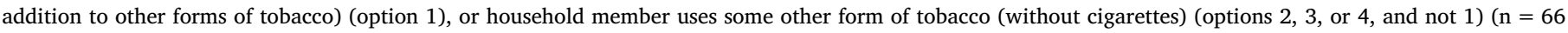
missing).

14 All youth were asked "During the past seven days, about how many hours were you around others who were smoking [whether or not you were smoking

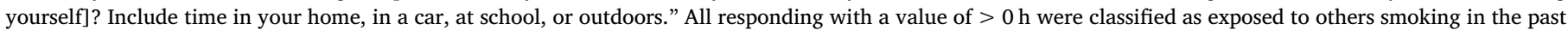
seven days ( $n=251$ missing).

\section{Discussion}

The public health consequences of e-cigarettes in the U.S. rests in large part on how youth are using the product and the subsequent effect on long-term tobacco use behaviors. In the current analysis, we: (1) observed differences and similarities for known cigarette smoking risk factors across mutually exclusive groups of susceptibility and ever use of e-cigarettes and cigarettes; (2) describe patterns of use among current e-cigarette users at Wave 1 ; and (3) describe the baseline risk factors among new users at follow up.

At baseline, youth susceptible to both products reported more and stronger associations with traditional risk factors than those susceptible to one product. Those susceptible to a single product, however, still showed increased risk status compared to committed never users. In general, committed never users had the lowest odds of any of the studied risk factors, while selected risk factors (ever other tobacco/ marijuana/ alcohol use, low academic achievement, and exposure to tobacco use) were significantly associated with single product use (ecigarette or cigarette), consistent with previously reported research. (Leventhal et al., 2016; Wills et al., 2015) Ever dual users had higher odds of nearly all risk factors compared to ever e-cigarette only use. We examined baseline risk factor distributions among groups defined by Wave 1 to Wave 2 transitions. Compared to continued non-users, a significantly higher proportion of new users reported being older, ever using marijuana and alcohol, having more internalizing, externalizing, and sensation seeking behaviors, having lower grades, and having someone in the household who uses tobacco.

The intent of this paper was to compare the distribution of traditional risk factors among e-cigarette and cigarette susceptibility and ever user groups at baseline to provide in-depth comparison of such risk factors, which provides pertinent information for future longitudinal analyses of the PATH Study data. At baseline, while ever dual users had increased odds of reporting all risk factors compared to ever e-cigarette only users, ever cigarette only users either had similar odds (no significant difference) of reporting each risk factor or the effect was small (e.g., the borderline significant findings could be influenced by further adjustment rendering non-significant differences). Therefore, we examined the distribution of the traditional cigarette smoking risk factors among youth who had never used tobacco at baseline, but were new ecigarette, cigarette, and dual users at Wave 2 follow-up. These new users demonstrated similar distributions for each risk factor among three new user groups, and in conjunction with the non-significant findings for some risk factors among ever users groups at baseline, suggests a shared vulnerability for tobacco product use between the user groups.

Given the purpose of this manuscript, we did not intend to make causal interpretations in this study. The overlap in known risk factors among ever e-cigarette and cigarette users (such as ever marijuana and other tobacco use) suggest single product users are similar on some risk factors. Additionally, similarities in scores on the psychosocial scales (GAIN Internalizing, GAIN Externalizing, and Sensation seeking) could support the notion that youth who participate in high-risk behaviors and may otherwise have smoked cigarettes may be using e-cigarettes instead. Nonetheless, some differences were observed between ever ecigarette and cigarette users on other risk factors, which may suggest that e-cigarettes could be attracting youth with lower risk status.

Previous studies have assessed similarities and differences in risk factors associated with ever e-cigarette and cigarette use, and have highlighted the importance of internalizing, externalizing, and substance use behaviors among youth tobacco users. In our large, nationally representative study, consistent with prior research,(BarringtonTrimis et al., 2015; Leventhal et al., 2016; Wills et al., 2015) we found higher internalizing scores among dual users, but similar scores among ever e-cigarette and cigarette users.(Leventhal et al., 2016) We saw no differences in externalizing scores by user group. Lastly, sensation seeking had an ordered pattern, with ever dual users having the greatest percentage of high sensation-seeking scores, followed by ever cigarette users and e-cigarette users, consistent with previous results.(Wills et al., 2015)

Ever dual users and cigarette smokers had higher odds of high GAIN 
Table 3

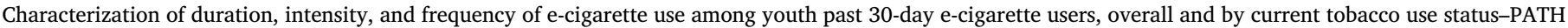
Study Wave 1 Data (2013-2014).

\begin{tabular}{|c|c|c|c|c|c|}
\hline & $\begin{array}{l}\text { Overall }^{1} \\
n=398 \\
(3.0 \% \text { of full } \\
\text { sample })\end{array}$ & $\begin{array}{l}\text { Past 30-Day } \\
\text { E-Cigarette Only } \\
\text { Users }^{2} \\
n=141(37.0 \%)\end{array}$ & $\begin{array}{l}\text { Past 30-Day } \\
\text { E-Cigarette Users + Cigarette } \\
\text { Smokers }^{3} \\
n=190(45.1 \%)\end{array}$ & $\begin{array}{l}\text { Past 30-Day } \\
\text { E-Cigarette }+ \text { Other (Non-Cigarette) } \\
\text { Tobacco Users }{ }^{4} \\
n=67(17.8 \%)\end{array}$ & Chi-Square $^{11}$ \\
\hline & $\begin{array}{l}\mathrm{n}(\%) \\
{[95 \% \mathrm{CI}]}\end{array}$ & $\begin{array}{l}\mathrm{n}(\%) \\
{[95 \% \mathrm{CI}]}\end{array}$ & $\begin{array}{l}\mathrm{n}(\%) \\
{[95 \% \mathrm{CI}]}\end{array}$ & $\begin{array}{l}\mathrm{n}(\%) \\
{[95 \% \mathrm{CI}]}\end{array}$ & \\
\hline Current Age & & & & & 0.6747 \\
\hline $12-14$ years & $\begin{array}{l}73(16.6 \%) \\
{[13.2-20.6]}\end{array}$ & $\begin{array}{l}30(18.9 \%) \\
{[13.3-26.3]}\end{array}$ & $\begin{array}{l}31(15.2 \%) \\
{[10.5-21.4]}\end{array}$ & $\begin{array}{l}12(15.4 \%) \\
{[8.5-26.3]}\end{array}$ & \\
\hline $15-17$ years & $\begin{array}{l}325(83.4 \%) \\
{[79.4-86.8]}\end{array}$ & $\begin{array}{l}111(81.1 \%) \\
{[73.7-86.7]}\end{array}$ & $\begin{array}{l}159(84.8 \%) \\
{[78.6-89.5]}\end{array}$ & $\begin{array}{l}55(84.6 \%) \\
{[73.7-91.5]}\end{array}$ & \\
\hline Cumulative History of E-cigarette Use ${ }^{5}$ & & & & & 0.0108 \\
\hline 1 puff, never a whole e-cigarette & $\begin{array}{l}121(31.1 \%) \\
{[26.4-36.2]}\end{array}$ & $\begin{array}{l}57(40.3 \%) \\
{[30.9-50.5]}\end{array}$ & $\begin{array}{l}43(23.9 \%) \\
{[18.2-30.7]}\end{array}$ & $\begin{array}{l}21(30.1 \%) \\
{[20.4-42.1]}\end{array}$ & \\
\hline 1-10 e-cigarette(s) & $\begin{array}{l}208(52.7 \%) \\
{[47.1-58.3]}\end{array}$ & $\begin{array}{l}68(50.0 \%) \\
{[39.6-60.4]}\end{array}$ & $\begin{array}{l}108(56.8 \%) \\
{[49.7-63.7]}\end{array}$ & $\begin{array}{l}32(47.8 \%) \\
{[34.8-61.1]}\end{array}$ & \\
\hline $11+$ e-cigarettes & $\begin{array}{l}67(16.2 \%) \\
{[12.7-20.5]}\end{array}$ & $\begin{array}{l}15(9.7 \%) \\
{[5.8-15.7]}\end{array}$ & $\begin{array}{l}39(19.3 \%) \\
{[14.0-26.0]}\end{array}$ & $\begin{array}{l}13(22.1 \%) \\
{[13.8-33.5]}\end{array}$ & \\
\hline Time Since First E-cigarette Use $^{6}$ & & & & & 0.0014 \\
\hline$<1$ year & $\begin{array}{l}193(50.6 \%) \\
{[45.3-55.9]}\end{array}$ & $\begin{array}{l}84(62.2 \%) \\
{[53.4-70.2]}\end{array}$ & $\begin{array}{l}73(39.2 \%) \\
{[32.4-46.5]}\end{array}$ & $\begin{array}{l}36(55.6 \%) \\
{[43.1-67.3]}\end{array}$ & \\
\hline $1-<2$ years & $\begin{array}{l}143(34.4 \%) \\
{[29.7-39.4]}\end{array}$ & $\begin{array}{l}41(28.3 \%) \\
{[20.8-37.3]}\end{array}$ & $\begin{array}{l}79(39.9 \%) \\
{[32.7-47.6]}\end{array}$ & $\begin{array}{l}23(33.2 \%) \\
{[22.3-46.1]}\end{array}$ & \\
\hline$\geq 2$ years & $\begin{array}{l}61(15.0 \%) \\
{[11.8-18.8]}\end{array}$ & $\begin{array}{l}15(9.5 \%) \\
{[5.7-15.5]}\end{array}$ & $\begin{array}{l}38(20.9 \%) \\
{[15.2-28.0]}\end{array}$ & ศ & \\
\hline $\begin{array}{l}\text { Frequency of Past 30-Day E-cigarette } \\
\quad \text { Use }^{7}\end{array}$ & & & & & 0.0612 \\
\hline 1 day & $\begin{array}{l}121(30.8 \%) \\
{[26.1-36.0]}\end{array}$ & $\begin{array}{l}56(40.4 \%) \\
{[32.1-49.2]}\end{array}$ & $\begin{array}{l}47(25.2 \%) \\
{[19.3-32.2]}\end{array}$ & $\begin{array}{l}18(25.4 \%) \\
{[16.0-37.9]}\end{array}$ & \\
\hline $2-5$ days & $\begin{array}{l}165(42.6 \%) \\
{[37.0-48.3]}\end{array}$ & $\begin{array}{l}53(38.2 \%) \\
{[30.1-46.9]}\end{array}$ & $\begin{array}{l}84(46.0 \%) \\
{[38.8-53.5]}\end{array}$ & $\begin{array}{l}28(42.8 \%) \\
{[30.4-56.1]}\end{array}$ & \\
\hline $6-20$ days & $\begin{array}{l}74(18.5 \%) \\
{[14.8-22.9]}\end{array}$ & $\begin{array}{l}24(17.2 \%) \\
{[11.6-24.8]}\end{array}$ & $\begin{array}{l}36(17.9 \%) \\
{[13.1-24.0]}\end{array}$ & $\begin{array}{l}14(22.7 \%) \\
{[13.5-35.5]}\end{array}$ & \\
\hline 21-30 days & $\begin{array}{l}33(8.1 \%) \\
{[5.4-11.9]}\end{array}$ & ศ & $\begin{array}{l}22(10.8 \%) \\
{[7.0-16.4]}\end{array}$ & ๆ & \\
\hline Owns an E-cigarette ${ }^{8}$ & $\begin{array}{l}125(31.6 \%) \\
{[27.2-36.5]}\end{array}$ & $\begin{array}{l}34(23.6 \%) \\
{[17.3-31.2]}\end{array}$ & $\begin{array}{l}66(34.0 \%) \\
{[27.6-41.0]}\end{array}$ & $\begin{array}{l}25(42.5 \%) \\
{[30.8-55.1]}\end{array}$ & 0.0132 \\
\hline Cigarette Smoking Status & & & & & $n / a$ \\
\hline Never smoker & $\begin{array}{l}90(23.6 \%) \\
{[19.4-28.3]}\end{array}$ & $\begin{array}{l}67(46.7 \%) \\
{[38.6-55.1]}\end{array}$ & - & $\begin{array}{l}23(35.1 \%) \\
{[23.1-49.2]}\end{array}$ & \\
\hline $\begin{array}{l}\text { Ever smoked a cigarette, but not within } \\
\text { past month }\end{array}$ & $\begin{array}{l}118(31.3 \%) \\
{[26.2-36.9]}\end{array}$ & $\begin{array}{l}74(53.3 \%) \\
{[44.9-61.4]}\end{array}$ & - & $\begin{array}{l}44(64.9 \%) \\
{[50.8-76.9]}\end{array}$ & \\
\hline Current Smoker $^{9}$ & $\begin{array}{l}190(45.1 \%) \\
{[40.2-50.1]}\end{array}$ & - & $190(100.0 \%)$ & - & $n / a$ \\
\hline $\begin{array}{l}\text { Past } 30 \text {-day smoker, smoked } 1-5 \text { days } \\
\text { during past month }\end{array}$ & - & - & $\begin{array}{l}73(40.8 \%) \\
{[32.4-49.8]}\end{array}$ & - & \\
\hline $\begin{array}{l}\text { Past 30-day smoker, smoked 6-19 days } \\
\text { during past month }\end{array}$ & - & - & $\begin{array}{l}38(19.6 \%) \\
{[14.5-25.9]}\end{array}$ & - & \\
\hline $\begin{array}{l}\text { Past } 30 \text {-day smoker, smoked } \geq 20 \text { days } \\
\text { during past month }\end{array}$ & - & - & $\begin{array}{l}74(39.6 \%) \\
{[31.6-48.3]}\end{array}$ & - & \\
\hline Use of Flavored E-cigarettes & & & & & \\
\hline First e-cigarette tried was flavored ${ }^{10}$ & $\begin{array}{l}340(86.6 \%) \\
{[82.7-89.8]}\end{array}$ & $\begin{array}{l}127(90.3 \%) \\
{[83.9-94.4]}\end{array}$ & $\begin{array}{l}153(82.0 \%) \\
{[75.9-86.8]}\end{array}$ & $\begin{array}{l}60(90.7 \%) \\
{[81.1-95.7]}\end{array}$ & 0.0565 \\
\hline $\begin{array}{l}\text { E-cigarette currently/most recently used } \\
\text { was } \\
\text { flavored }^{10}\end{array}$ & $\begin{array}{l}341(86.2 \%) \\
{[81.3-90.0]}\end{array}$ & $\begin{array}{l}125(88.2 \%) \\
{[80.4-93.1]}\end{array}$ & $\begin{array}{l}156(83.2 \%) \\
{[76.0-88.6]}\end{array}$ & $\begin{array}{l}60(89.7 \%) \\
{[78.5-95.4]}\end{array}$ & 0.3658 \\
\hline
\end{tabular}

- Estimate not presented because relative standard error $\geq 30 \%$ or denominator $<50$; - not applicable.

$1 \mathrm{n}=20$ who responded they had used in the past 30 days, but later reported using 0 out of the past 30 days are excluded from this table.

2 Any past 30-day e-cigarette user who reported also using cigarettes, any type of cigar, snus, smokeless, hookah, pipe, dissolvables, bidis or kreteks in the past

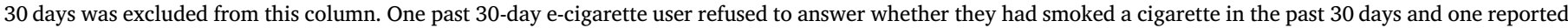

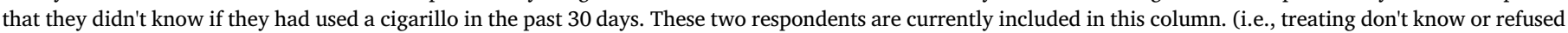
as no's).

${ }^{3}$ Any past 30-day e-cigarette users who also reported past 30-day cigarette smoking and past 30-day use of any type of cigar, snus, smokeless, hookah, pipe, dissolvables, bidis or kreteks were included in this column.

4 Any past 30-day e-cigarette user who reported NO past 30-day use of cigarettes, but past-30-day use of any type of cigar, snus, smokeless, hookah, pipe, dissolvables, bidis or kreteks were included in this column.

5 Cumulative history of e-cigarette use: $\mathrm{n}=2$ missing/don't know/refused.

6 Time since first use of an e-cigarette was calculated by subtracting YE1006 ("How old were you when you first tried an e-cigarette, even one or two times?") from current age. $\mathrm{N}=1$ reported don't know to age started using.

7 Frequency of past 30-day e-cigarette use: $\mathrm{n}=2$ refused to answer, $\mathrm{n}=2$ replied "don't know" and $\mathrm{n}=1$ was coded as "improbable response removed."

8 "Do you own your own e-cigarette?" (YE1090): $\mathrm{n}=3$ missing (refused to answer). 
9 Current smoking status (past 30-days): $\mathrm{n}=5$ missing smoking status ( $\mathrm{n}=2$ don't know, $\mathrm{n}=2$ refused, and $\mathrm{n}=1$ improbable response removed), as these youth did not give an answer for the number of days smoked in the past 30 days.

10 "Flavored to taste like menthol, mint, clove, spice, candy, fruit, chocolate, alcohol (such as wine or cognac), or other sweets?" (YE1108 and YE1130): n = 1 missing first e-cigarette was flavored, 0 missing e-cigarette used most recently was flavored.

11 P-value is a Rao-Scott chi-square testing differences between groups. Bold $=$ significant at $\mathrm{p}=0.05$.

substance use scores than ever e-cigarette users, with the largest percentage of high scores seen among ever dual users, which is a common theme in previous research.(Leventhal et al., 2016; Wills et al., 2015) There was a similar pattern observed for marijuana use, although findings in this area have been mixed in previous studies.(Leventhal et al., 2016; Wills et al., 2015) Our finding of ever dual users having the highest percentage of alcohol use, with similar use in cigarette and ecigarette single product users, has been previously reported.(Leventhal et al., 2016; Wills et al., 2015) Ever cigarette only smokers and dual users had higher odds of being exposed to a household member who smokes compared to ever e-cigarette only users, as previously reported. (Barrington-Trimis et al., 2015)

In our study, about $74 \%$ of past 30-day e-cigarette users used ecigarettes fewer than five days at baseline (2013-2014), similar to national data from both the 2014 National Youth Tobacco Survey(Neff, Arrazola, Caraballo, et al., 2015) and the 2014 Monitoring the Future survey,(Warner, 2016) and to regional data.(Bold, Kong, Camenga, et al., 2018) Among all past 30-day e-cigarette users, over $80 \%$ had used $<10$ times ever, indicating that at baseline many youth users may have started in the past year. However, past 30-day e-cigarette users who also used other tobacco products appeared to be more consistent ecigarette users. Past 30-day dual users reported a greater cumulative history of e-cigarette use (i.e., higher number used), a longer time since first using e-cigarettes, and more frequent e-cigarette use. Additionally, about half of past 30-day dual users also smoked cigarettes on $>15$ days. Similar reasons for e-cigarette use were observed when stratified by smoking status; however, dual users were more likely to report items related to health effects or avoidance of detection of e-cigarette use.

This study has several limitations. First, this study did not address all factors associated with youth tobacco use (e.g. product availability in home, marketing exposure), some possibly unique to e-cigarette use. Subsequent waves of the PATH Study may capture such information. Second, tobacco use, including e-cigarette and cigarette use, is self-reported, which may be subject to biases (i.e., response or self-report bias); however, such measures have been shown to be valid and reliable among youth and adult cigarette smokers.(Brener, Billy, \& Grady, 2003; Wong, Shields, Leatherdale, Malaison, \& Hammond, 2012) Third, the associations and significance tests were not adjusted for multiple comparisons. Based on the number of models conducted, a Bonferroni corrected $\mathrm{p}$-value of $\mathrm{p}=0.05$ would be $\mathrm{p}=0.004$. Nonetheless, most odds ratios were significant at the $p=0.001$. Fourth, Wave 1 of the PATH Study may not have captured the full range of electronic nicotine devices, which could result in underreporting of e-cigarette use. Lastly, susceptibility to and ever use of tobacco products other than e-cigarettes and cigarettes were not considered when defining the mutually exclusive groups.

\section{Conclusion}

This manuscript adds to the literature by describing the distribution of traditional risk factors for cigarette smoking among youth susceptible to or ever users of e-cigarettes or cigarettes using a nationally-representative sample. In this study, committed never users had the lowest odds of any risk factor, followed by those susceptible to single product use, then those susceptible to both products. Compared to ecigarette only users, dual users had higher odds of other tobacco, alcohol, and marijuana use, internalizing problems, low academic achievement, and exposure to others' tobacco use. Ever cigarette smokers had higher odds of other tobacco use, marijuana use, high GAIN substance scores, lower academic achievement, and exposure to others smoking than e-cigarette only users, but the increased odds were lower than those observed for dual users. No differences were observed in the ever use groups for GAIN externalizing, sensation seeking, or household use of other tobacco. This analysis may inform future studies examining transitions between products and assessing the influence of risk factors on the probability of progression to regular tobacco use.

\section{Role of funding sources}

This manuscript is supported with federal funds from the National Institute on Drug Abuse, National Institutes of Health, and the and the Center for Tobacco Products, Food and Drug Administration, Department of Health and Human Services, under contract to Westat (Contract \# HHSN271201100027C).

\section{Contributors}

MDS, HRD, and BKA designed the study and directed its implementation. HRD, LDG, and HH conducted the data analysis, including quality assurance and control. SEJ, BC, JL, MLG, DBA, CAS, JLP, ARK, HLK, CDD, WMC, MB-T, RSN, AH, and BKA contributed to the conceptual design of the study and assisted with drafting of the manuscript (e.g., preparing the literature review, identifying key findings and interpretation of study findings in the Discussion section). All coauthors approved the final version of the manuscript prior to submission.

\section{Acknowledgments}

The authors wish to thank Dr. Karen Messner, who assisted in the conceptualization of the project.

\section{Disclaimer}

The views and opinions expressed in this manuscript are those of the authors only and do not necessarily represent the views, official policy or position of the U.S. Department of Health and Human Services or any of its affiliated institutions or agencies.

\section{Appendix A. Supplementary data}

Supplementary data to this article can be found online at https:// doi.org/10.1016/j.addbeh.2018.11.027.

\section{References}

Barrington-Trimis, J. L., Berhane, K., Unger, J. B., et al. (2015). Psychosocial factors associated with adolescent electronic cigarette and cigarette use. Pediatrics, 136(2), 308-317. https://doi.org/10.1542/peds.2015-0639.

Bold, K. W., Kong, G., Camenga, D. R., et al. (2018). Trajectories of E-cigarette and conventional cigarette use among youth. Pediatrics, 141(1), https://doi.org/10.1542/ peds.2017-1832.

Brener, N. D., Billy, J. O., \& Grady, W. R. (2003). Assessment of factors affecting the validity of self-reported health-risk behavior among adolescents: Evidence from the scientific literature. The Journal of Adolescent Health : Official Publication of the Society for Adolescent Medicine, 33(6), 436-457.

Conway, K. P., Green, V. R., Kasza, K. A., et al. (2018). Co-occurrence of tobacco product use, substance use, and mental health problems among youth: Findings from wave 1 (2013-2014) of the Population Assessment of Tobacco and Health (PATH) study. Addictive Behaviors, 76, 208-217. https://doi.org/10.1016/j.addbeh.2017.08.009.

Dennis, M. L., Chan, Y. F., \& Funk, R. R. (2006). Development and validation of the Gain Short Screener (GSS) for internalizing, externalizing and substance use disorders and crime/violence problems among adolescents and adults. The American Journal on Addictions, (s1), 15. 
Hampson, S. E., Andrews, J. A., Severson, H. H., \& Barckley, M. (2015). Prospective predictors of novel tobacco and nicotine product use in emerging adulthood. Journal of Adolescent Health, 57(2), 186-191. https://doi.org/10.1016/j.jadohealth.2015.04. 015 .

Hoyle, R. H., Stephenson, M. T., Palmgreen, P., Lorch, E. P., \& Donohew, R. L. (2002). Reliability and validity of a brief measure of sensation seeking. Personality and Individual Differences, 32(3), 401-414. https://doi.org/10.1016/S0191-8869(01) 00032-0.

Hyland, A., Ambrose, B. K., Conway, K. P., et al. (2017). Design and methods of the Population Assessment of Tobacco and Health (PATH) study. Tobacco Control, 26(4), 371-378. https://doi.org/10.1136/tobaccocontrol-2016-052934.

Jamal, A., Gentzke, A., Hu, S., et al. (2017). Tobacco use among middle and high school students-United States, 2011-2016. MMWR Morbidity and mortality weekly report 66(23), 597. https://doi.org/10.15585/mmwr.mm6623a1.

Kozlowski, L. T., \& Warner, K. E. (2017). Adolescents and e-cigarettes: Objects of concern may appear larger than they are. Drug \& Alcohol Dependence. 174, 209-214. https:// doi.org/10.1016/j.drugalcdep.2017.01.001.

Kwon, E., Seo, D.-C., Lin, H.-C., \& Chen, Z. (2018). Predictors of youth e-cigarette use susceptibility in a U.S. Nationally representative sample. Addictive Behaviors, 82 79-85. https://doi.org/10.1016/j.addbeh.2018.02.026.

Leventhal, A. M., Strong, D. R., Sussman, S., et al. (2016). Psychiatric comorbidity in adolescent electronic and conventional cigarette use. Journal of Psychiatric Research, 73, 71-78. https://doi.org/10.1016/j.jpsychires.2015.11.008 Supplement C.

Miech, R. A., Johnston, L. D., O'Malley, P. M., Bachman, J. G., \& Schulenberg, J. E. (2016). Monitoring the future national survey results on drug use, 1975-2015: Volume I, secondary school students.

National Academies of Sciences, Engineering, and Medicine (2018). Public health consequences of e-cigarettes. Washington, DC: The National Academies Press. (978-0-30946831-2) https://www.nap.edu/catalog/24952/public-health-consequences-of-ecigarettes.

Neff, L. J., Arrazola, R. A., Caraballo, R. S., et al. (2015). Frequency of tobacco use among middle and high school students - United States, 2014. Mmwr-Morbid Mortal W, 64(38), 1061-1065.

Pierce, J. P., Choi, W. S., Gilpin, E. A., Farkas, A. J., \& Merritt, R. K. (1996). Validation of susceptibility as a predictor of which adolescents take up smoking in the United States. Health Psychology : Official Journal of the Division of Health Psychology, American Psychological Association, 15(5), 355-361.

Pierce, J. P., Sargent, J. D., White, M. M., et al. (2017). Receptivity to tobacco advertising and susceptibility to tobacco products. Pediatrics, 139(6), https://doi.org/10.1542/ peds.2016-3353.

Soneji, S., Barrington-Trimis, J. L., Wills, T. A., et al. (2017). Association between initial use of e-cigarettes and subsequent cigarette smoking among adolescents and young adults: A systematic review and meta-analysis. JAMA Pediatrics, 171(8), 788-797. https://doi.org/10.1001/jamapediatrics.2017.1488.

Soneji, S. S., Sung, H.-Y., Primack, B. A., Pierce, J. P., \& Sargent, J. D. (2018). Quantifying population-level health benefits and harms of e-cigarette use in the United States. PLoS One, 13(3), e0193328. https://doi.org/10.1371/journal.pone.0193328.

U.S. Department of Health and Human Services (2016). E-cigarette use among youth and young adults. A report of the Surgeon generalhttps://e-cigarettes.surgeongeneral.gov/ documents 2016 sgr full report non-508.pdf.

U.S. Department of Health and Human Services, National Institutes of Health, National Institute on Drug Abuse, United States Department of Health Human Services, Food Drug Administration, \& Center for Tobacco Products (2017). Population Assessment of Tobacco and Health (PATH) study restricted-use files. https://doi.org/10.3886/ ICPSR36231.v13.

Warner, K. E. (2016). Frequency of E-cigarette use and cigarette smoking by American students in 2014. American Journal of Preventive Medicine, 51(2), 179-184. https:// doi.org/10.1016/j.amepre.2015.12.004.

Wills, T. A., Knight, R., Sargent, J. D., Gibbons, F. X., Pagano, I., \& Williams, R. J. (2017). Longitudinal study of e-cigarette use and onset of cigarette smoking among high school students in Hawaii. Tobacco Control, 26(1), 34-39. https://doi.org/10.1136/ tobaccocontrol-2015-052705.

Wills, T. A., Knight, R., Williams, R. J., Pagano, I., \& Sargent, J. D. (2015). Risk factors for exclusive e-cigarette use and dual e-cigarette use and tobacco use in adolescents. Pediatrics, 135(1), E43-E51. https://doi.org/10.1542/peds.2014-0760.

Wong, S. L., Shields, M., Leatherdale, S., Malaison, E., \& Hammond, D. (2012). Assessment of validity of self-reported smoking status. Health Reports, 23(1), 47-53. 